Article

\title{
Human-Wildlife Conflict at a Suburban-Wildlands Interface: Effects of Short- and Long-Distance Translocations on Red Diamond Rattlesnake (Crotalus ruber) Activity and Survival
}

\author{
Aaron G. Corbit ${ }^{1,2, * \mathbb{D}}$ and William K. Hayes ${ }^{1} \mathbb{D}$ \\ 1 Department of Earth and Biological Sciences, School of Medicine, Loma Linda University, \\ Loma Linda, CA 92350, USA; whayes@llu.edu \\ 2 Biology/Allied Health Department, Southern Adventist University, Collegedale, TN 37315, USA \\ * Correspondence: acorbit@southern.edu
}

check for

updates

Citation: Corbit, A.G.; Hayes, W.K

Human-Wildlife Conflict at a

Suburban-Wildlands Interface:

Effects of Short- and Long-Distance Translocations on Red Diamond

Rattlesnake (Crotalus ruber) Activity and Survival. Diversity 2022, 14, 130 . https://doi.org/10.3390/d14020130

Academic Editors: Michael Wink

Michael J. Dreslik, Sarah J. Baker and Gordon W. Schuett

Received: 1 January 2022

Accepted: 25 January 2022

Published: 11 February 2022

Publisher's Note: MDPI stays neutral with regard to jurisdictional claims in published maps and institutional affiliations.

Copyright: (C) 2022 by the authors. Licensee MDPI, Basel, Switzerland. This article is an open access article distributed under the terms and conditions of the Creative Commons Attribution (CC BY) license (https:// creativecommons.org/licenses/by/ $4.0 /)$

\begin{abstract}
The mitigation of human-rattlesnake conflicts often involves euthanizing or translocating the offending rattlesnake. Although translocation is generally considered more humane, especially by the general public, it may negatively impact the translocated individual and may not be effective if that individual returns to areas where the probability of human conflict is high. We used radiotelemetry to experimentally study the effects of short- (SDT) and long-distance translocation (LDT; beyond the typical home range or activity range) on adult Red Diamond Rattlesnakes (Crotalus ruber) near a residential development in Southern California. Though the results were mixed, some analyses suggested that higher numbers of SDTs were associated with larger activity areas and increased movement. For snakes undergoing LDT, the activity areas and mean daily movement distances were 1.8-4.6 times larger than those of non-LDT snakes in the year of translocation, but were similar in the following year. Cox regression models revealed that, for both LDT and non-LDT snakes, every $1 \mathrm{~m}$ increase in the distance moved resulted in a 1.2\% decreased risk of moving back into a human-modified area and a 1.6\% decreased risk of returning to the original site of conflict. We failed to detect an effect of either LDT or SDT on body mass change or survival. Our findings suggest that LDT of nuisance snakes may be a viable option for at least some rattlesnake populations or species, especially those in which individuals do not require communal overwintering sites.
\end{abstract}

Keywords: reptiles; Serpentes; snakes; Viperidae; Crotalinae; human-wildlife coexistence; urban ecology; mortality

\section{Introduction}

As human development encroaches on natural areas, human interactions and conflicts with native wildlife increase [1-5]. In many cases, conflict can provide a basis for public interest in native species and their conservation, and promote coexistence. However, these interactions too often become undesirable, with wildlife either causing property damage or injury to humans, or being perceived as causing such. Three options exist to mitigate human-wildlife conflicts: (1) limit human access to conflict areas; (2) remove the offending animals; or (3) learn to tolerate the conflict. Limiting human access to potential conflict areas has proven effective at minimizing disturbance to wildlife and risks to humans [6-8]. Limiting access, however, is predicated on identifying conflict areas and having the legal authority to limit access. The latter becomes particularly acute when nuisance wildlife moves onto private property, as a person's access to their property cannot be limited. In such cases, removing the offending animal is the only option, apart from doing nothing, though education can enhance tolerance.

Animals removed from conflict with humans are dealt with either by euthanization or translocation [5,9]. Translocation refers to physically moving one or more individuals and broadly covers many practices, such as establishing, reestablishing, or augmenting 
populations [10-12]. Mitigation translocation, the practice of moving nuisance wildlife to areas where conflict with humans no longer exists [13-15], is preferred and more humane than euthanization [14]. However, many studies examining the effects of translocation urge caution because of increased mortality, ineffectiveness, and/or negative effects on other wildlife. Translocated animals often exhibit erratic movements and suffer high mortality rates, at least in the short-term [5,13,16-27], and may also experience elevated stress [28]. Additionally, translocated animals could return to the original area or move into a new conflict area [13,16,29-33]. Finally, translocated animals may negatively affect resident wildlife by introducing disease, disrupting their social structure, or contributing to outbreeding depression [11,13,16,34-36]. Typically, animals subjected to short-distance translocation (SDT) suffer fewer consequences, but are more likely to return to conflict areas compared to animals subjected to long-distance translocation (LDT [16]).

In the United States, venomous snakes often come into conflict with humans [37,38]. Even though public perception of the risk may be inflated [31,39], they do represent a legitimate risk. Mortality from venomous snakebites in the U.S. is low (five to seven deaths annually), but it remains a significant medical issue, with an estimated 2683-3858 envenomations annually [40]. These envenomations incur substantial costs and physical and emotional distress [41-43]. Unfortunately for venomous snakes, there is some public support for euthanizing nuisance animals [44]. Because venomous snakes are chiefly top-order predators, indiscriminate euthanization is problematic as the loss of individuals could have ecological ramifications $[13,45,46]$. Euthanization may also be problematic when the nuisance species is endangered or protected, thereby countering conservation efforts and contradicting legal mandates [37]. Because SDT can alleviate the negative effects of translocation [16], it may effectively manage nuisance rattlesnakes [47], especially when the measures are to reduce the chance of return to conflict areas [48]. Despite one author reporting success with SDT [37], others have reported snakes returning to conflict areas $[31,49,50]$.

Despite a number of studies examining translocation in rattlesnakes, many have methodological weaknesses. Several studies used radiotelemetry to monitor venomous snakes translocated for establishing or reestablishing populations [51-58]. While such studies provide valuable information on the behavior of translocated snakes, they lack nontranslocated (NT) control snakes. Other studies have used mark/recapture methods [31], but such methods are poorly suited for determining snake mortality and how often snakes return undetected to conflict areas. A few studies have used radiotelemetry and appropriate control groups. Most of these studies revealed increased movements and size of activity areas in LDT relative to SDT snakes [28,49,50,59-62]. Some studies further concluded that LDT snakes suffered higher mortality [48,59], whereas others did not [49]. To date, no studies have directly compared SDT, LDT, and NT snakes. Although Brown et al. [49] attempted to compare all three groups, the unfortunate deaths of two of three SDT snakes due to surgical complications precluded statistical analyses.

In this study, we used radiotelemetry to experimentally examine the effects of SDT and LDT on the survival and spatial ecology of adult Red Diamond Rattlesnakes (Crotalus ruber) to inform future policies for dealing with nuisance rattlesnakes. Because the species is protected in southern California due to anthropogenic threats [63], euthanization is undesirable as an option for mitigating human-wildlife conflicts. Although several criteria have been used to distinguish SDT and LDT in rattlesnakes (e.g., [31,47-49]), we considered SDT to be within and LDT to be beyond the typical home range or activity range of individuals in the study population.

\section{Materials and Methods}

\subsection{Study Site}

We conducted the study in the southern portion of Loma Linda, California $\left(34^{\circ} 02^{\prime} \mathrm{N}\right.$, $117^{\circ} 16^{\prime} \mathrm{W}$ ), within a ca. 500 ha boundary area between a suburban residential area to the north and a largely undeveloped area of rolling hills (ca. $324 \mathrm{~km}^{2}$ ) extending southeast 
(Figure 1). The portion containing natural habitat consisted largely of non-native grassland, with steeper north-facing slopes classified as coastal sage scrub dominated by California Sagebrush (Artemisia californica) and Black Sage (Salvia mellifera), and south-facing slopes populated by Brittlebush (Encelia farinosa). The site lacked the rock outcrops and substantial cactus patches preferred by C. ruber elsewhere $[64,65]$. Human development was largely residential, with sprinkler-irrigated lawns and gardens, and non-native tree species. The study area also contained small citrus orchards on the eastern end and a large cemetery on the western end, which included large trees and year-round sprinkler-irrigated lawns. The site experiences a Mediterranean climate [66], with much of the $34.4 \mathrm{~cm}$ average annual precipitation occurring during the winter and spring [67]. Winters are mild, with the mean daily low temperature in January being $4.1^{\circ} \mathrm{C}$. Summers are hot and dry, with the mean daily high temperature in July being $34.7^{\circ} \mathrm{C}$ [67].

\subsection{Legal Issues}

The study required cooperation from residents, who reported snakes and allowed access to their property. To solicit assistance, we distributed fliers to property owners bordering the natural habitat. Because our study involved potential liability due to the possibility of envenomation from our research subjects, we sought legal advice and developed a letter informing homeowners of the nature of our research. The letter included an agreement that allowed homeowners to specify their level of permission for us to access their property and their wishes regarding the protocol to follow when we discovered snakes on their property. Of the 28 homeowners that signed the agreement, 27 granted us access to their property and all requested that any accessible snakes be translocated away from their property. Homeowners were informed if a snake on their property was inaccessible (e.g., beneath wooden patios or concrete slabs). Thus, these legal issues necessarily constrained our study design, including our ability to assign snakes to an NT group.

\subsection{Radiotelemetry}

We began snake collection, radiotransmitter implantation, and tracking in July 2008 and continued through December 2011. We obtained most snakes through cooperating residents who contacted us when they discovered a rattlesnake on their property. We also collected snakes opportunistically when discovered in the field, especially during the spring mating season (February-April [64]). We determined sex by subcaudal scale count (male: $\geq 24$; female: $\leq 23$ ) and/or probing using Neosporin-lubricated sexing probes. We measured the total length via photography in a press box [68] with the floor covered by $1 \mathrm{~cm}$ graph paper. Photographs were imported into ImageJ version 1.47q [69] to calculate snake length. We measured snake mass initially, and again when we returned to the lab for transmitter replacement or injury, using a $2500 \mathrm{~g}$ Pesola spring scale (Pescola AG, Baar, Switzerland).

We implanted SI-2 (Holohil Systems Ltd., Ottawa, ON, Canada) and SOPB-2190 (Wildlife Materials Inc., Murphysboro, IL, USA) radiotransmitters that weighed ca. 6 and $9 \mathrm{~g}$, respectively, and always represented $<5 \%$ of an individual's body mass [60]. Surgical procedures followed the protocols established for snakes [70,71]. To reduce post-surgical mortality [70], we released the snakes soon (24-48 h) after surgery. We obtained fixes on each snake's location 1-2 times weekly using a Telonics TR2 receiver (Telonics, Mesa, AZ, USA) and a generic four- or six-element Yagi antenna. For each fix, we attempted to locate the snake visually and record its coordinates using a handheld GPS unit (Magellan Explorist 210; Magellan, Santa Clara, CA, USA). If a snake was not visible, we took the coordinates as close to the source of the strongest radio signal as possible. 

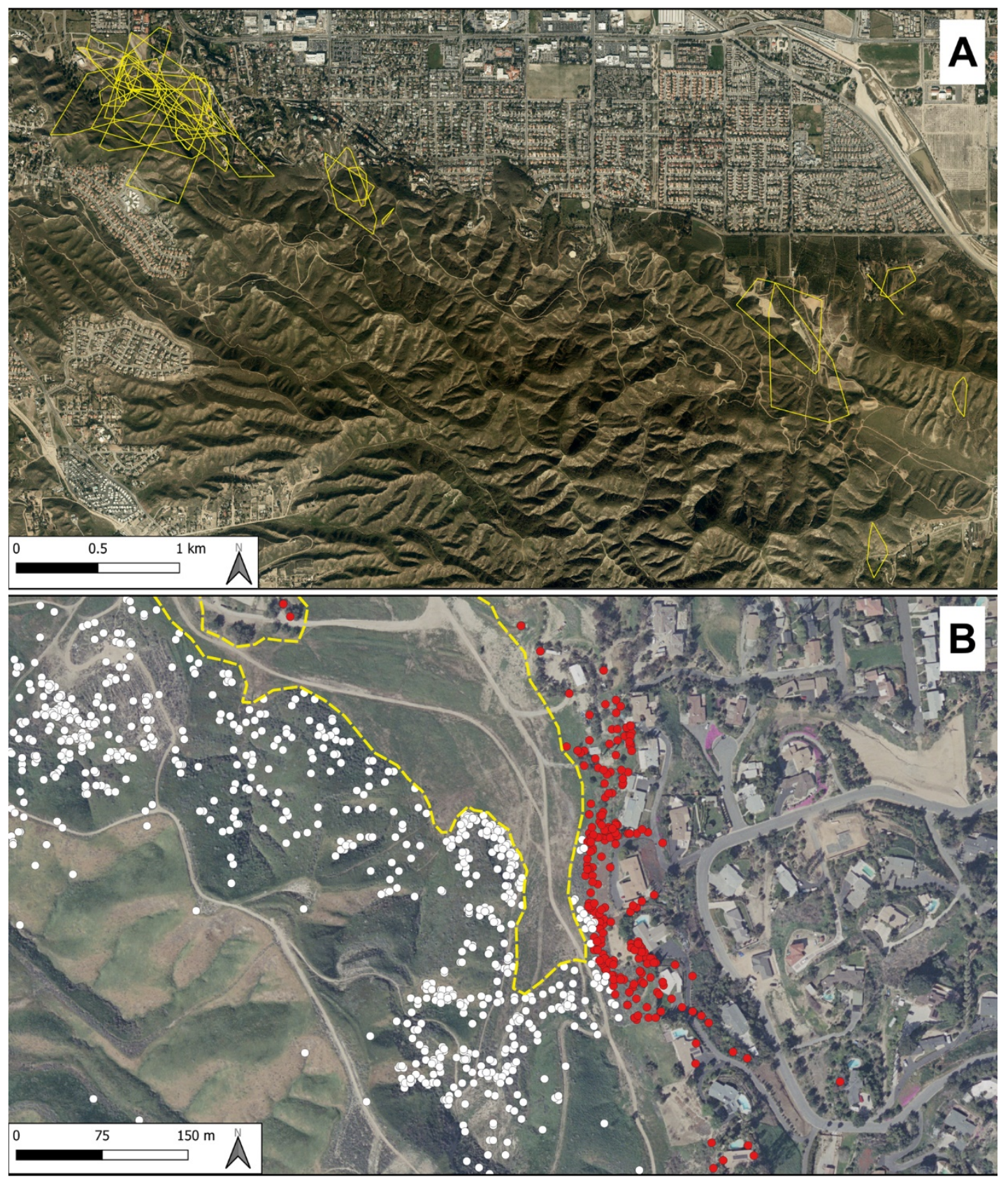

Figure 1. (A) Study site in Loma Linda, CA, USA, showing the $100 \%$ minimum convex polygons (MCPs) for all fixes of all radiotelemetered Red Diamond Rattlesnakes (Crotalus ruber) in the study with three or more unique fixes $(n=29)$. (B) Spatial depiction of a western portion of the study site. Radiotelemetry fixes (all snakes pooled) are shown for natural habitat (white circles) versus human-modified areas (red circles). Yellow dashes outline a plowed firebreak that the snakes moved across, but never stopped within.

\subsection{Translocation Protocol}

After transmitter implantation, we initially released snakes at either the site of capture if found in natural habitat, or 50-400 $\mathrm{m}$ away in the nearest natural habitat (SDTtranslocated) if caught in or near human-modified areas (usually at the landowner's request). Once released, the snakes were disturbed as little as possible when tracking their movements. However, because of the risk of injury to humans (and the snake), and for the legal reasons discussed above, we SDT-translocated (50-400 m) any accessible telemetered animal found on a homeowner's property or in areas where direct conflict with humans was 
deemed likely. Thus, snakes could be SDT-translocated more than once, and we recorded all such translocations.

In October 2009, we began randomly assigning some newly captured snakes to the LDT group. These snakes, with three exceptions (see below), were moved $\geq 716 \mathrm{~m}$ away from their capture site and into natural habitat. We adopted the $716 \mathrm{~m}$ criterion used by Brown et al. [49], who distinguished SDT and LDT based on the maximum straight-line distance between any two locations for non-translocated C. ruber at a study site relatively close to ours. In retrospect, the greatest straight-line distance of any non-LDT snake at our study site was $681 \mathrm{~m}$, supporting our interpretation that snakes assigned to the LDT group met the formal definition of long-distance translocation. No snakes were moved $>6 \mathrm{~km}$.

Deviations from the SDT/LDT schema included three snakes. One female (Snake 19, Table 1), initially translocated $519 \mathrm{~m}$, displayed erratic movements subsequent to release. Given that female C. ruber have significantly smaller home ranges than males [49], we interpreted these erratic movements as translocation out of her normal home range, and therefore re-assigned her to the LDT group. An additional female and male (Snakes 2 and 11 respectively, Table 1) in the eastern portion of the study site, where we had access issues, were reassigned 1 year later from the non-LDT group to the LDT group after we translocated them to the western portion of the study site. These two snakes, subjected to both the non-LDT and LDT conditions, were treated as separate snakes (Snakes 2.1 and 11.1, Table 1) in our analyses. Thus, we had minor pseudoreplication across, but not within, treatment groups; the latter would have been more problematic.

Table 1. Attributes and fates of the radio-tracked adult Red Diamond Rattlesnakes (Crotalus ruber) near Loma Linda, California, USA. LDT indicates whether the snake was translocated a long distance $(>716 \mathrm{~m}$ ) to a new location after transmitter implantation (yes or no). SDTs indicates the number of short-distance $(<716 \mathrm{~m})$ translocations. Dates indicate the range of telemetry data collection. Change in mass $(\Delta)$ represents the difference between the initial and last mass recorded if recaptured.

\begin{tabular}{|c|c|c|c|c|c|c|c|c|c|}
\hline I.D. & Sex & LDT & SDTs (\#) & First Date & Last Date & $\begin{array}{c}\text { Days } \\
\text { Tracked }\end{array}$ & $\begin{array}{l}\text { Total } \\
\text { Fixes }\end{array}$ & $\underset{(\%)}{\Delta \text { Mass }}$ & Fate \\
\hline 2 & 우 & No & 3 & $8 / 2 / 2008$ & $6 / 10 / 2009$ & 313 & 62 & -21.4 & Translocated to become snake 2.1 \\
\hline $2.1^{\mathrm{a}}$ & q & Yes & 0 & $10 / 14 / 2009$ & $10 / 21 / 2009$ & 14 & 5 & & Died-killed by human action \\
\hline 3 & 우 & No & 6 & $8 / 3 / 2008$ & $10 / 12 / 2011$ & 1145 & 180 & -7.1 & Transmitter removed, snake released \\
\hline 4 & q & No & 0 & $8 / 10 / 2008$ & $8 / 23 / 2009$ & 384 & 68 & 25.0 & Died—found depredated ${ }^{\mathrm{d}}$ \\
\hline 5 & $0^{7}$ & No & 1 & $8 / 27 / 2008$ & $2 / 16 / 2010$ & 539 & 92 & -19.2 & Died-second surgery complications \\
\hline 6 & $0^{7}$ & No & 13 & $8 / 27 / 2008$ & $10 / 12 / 2011$ & 1121 & 151 & 13.2 & Transmitter removed, snake released \\
\hline 7 & ㅇ & No & 1 & $9 / 1 / 2008$ & $9 / 15 / 2009$ & 382 & 63 & & Lost-suspected transmitter failure ${ }^{c}$ \\
\hline 10 & $\sigma^{7}$ & No & 1 & $9 / 16 / 2008$ & $12 / 8 / 2008$ & 88 & 3 & & Died-injury/surgery complications \\
\hline 11 & $\sigma^{7}$ & No & 4 & $10 / 9 / 2008$ & $10 / 14 / 2009$ & 350 & 52 & 0.0 & Translocated to become snake 11.1 \\
\hline $11.1^{\mathrm{a}}$ & $\sigma^{7}$ & Yes & 0 & $10 / 21 / 2009$ & $10 / 18 / 2011$ & 721 & 90 & 18.8 & Transmitter removed, snake released \\
\hline 12 & ㅇ & No & 2 & $10 / 9 / 2008$ & $5 / 7 / 2009$ & 212 & 34 & & Lost-suspected transmitter failure ${ }^{c}$ \\
\hline 13 & $\sigma^{7}$ & No & 1 & $10 / 21 / 2008$ & $11 / 21 / 2008$ & 36 & 6 & & Lost-suspected transmitter failure ${ }^{c}$ \\
\hline 14 & $0^{7}$ & No & 1 & $1 / 11 / 2009$ & $1 / 27 / 2009$ & 26 & 3 & & Died-suspected depredation ${ }^{\mathrm{d}}$ \\
\hline 15 & ㅇ & No & 1 & $1 / 26 / 2009$ & $7 / 31 / 2009$ & 193 & 31 & & Lost-suspected transmitter failure ${ }^{c}$ \\
\hline 16 & q & No & 1 & $3 / 13 / 2009$ & $10 / 11 / 2011$ & 929 & 165 & -32.1 & Transmitter removed, snake released \\
\hline 17 & ó & No & 3 & $3 / 19 / 2009$ & $1 / 28 / 2010$ & 215 & 42 & -35.2 & Died-illness \\
\hline 18 & $\sigma^{2}$ & No & 0 & $3 / 19 / 2009$ & $3 / 27 / 2009$ & 11 & 2 & & Lost-suspected transmitter failure ${ }^{c}$ \\
\hline $19^{b}$ & ㅇ & Yes & 8 & $10 / 14 / 2009$ & $10 / 17 / 2011$ & 706 & 131 & 27.3 & Transmitter removed, snake released \\
\hline 20 & $\sigma^{2}$ & No & 3 & $10 / 21 / 2009$ & $7 / 26 / 2011$ & 631 & 122 & & Died-killed by human action \\
\hline 21 & q & Yes & 13 & $4 / 7 / 2010$ & $10 / 11 / 2011$ & 559 & 80 & & Transmitter removed, snake released \\
\hline 22 & $0^{\pi}$ & Yes & 14 & $4 / 7 / 2010$ & $4 / 12 / 2011$ & 382 & 79 & 25.8 & Died-unknown cause \\
\hline 23 & $\sigma^{7}$ & No & 1 & $4 / 9 / 2010$ & $8 / 14 / 2011$ & 424 & 78 & 15.9 & Transmitter removed, snake released \\
\hline 24 & q & No & 1 & $5 / 13 / 2010$ & $12 / 1 / 2010$ & 204 & 45 & & Transmitter failed early; found alive on $10 / 21 / 2013$ \\
\hline 25 & $0^{7}$ & Yes & 5 & $4 / 27 / 2010$ & $10 / 11 / 2011$ & 516 & 92 & 10.0 & Lost-suspected transmitter failure ${ }^{c}$ \\
\hline 26 & $\sigma^{7}$ & No & 10 & $4 / 27 / 2010$ & $12 / 30 / 2011$ & 608 & 103 & 13.3 & Not recaptured \\
\hline 27 & $\sigma^{7}$ & No & 8 & $6 / 10 / 2010$ & $12 / 30 / 2011$ & 550 & 83 & 102.9 & Not recaptured \\
\hline 28 & $\sigma^{7}$ & Yes & 1 & $6 / 10 / 2010$ & $10 / 18 / 2011$ & 480 & 46 & -2.6 & Transmitter removed, snake released \\
\hline 29 & প & No & 3 & $7 / 6 / 2010$ & $6 / 15 / 2011$ & 350 & 65 & & Lost-suspected transmitter failure ${ }^{c}$ \\
\hline 30 & $\stackrel{+}{+}$ & No & 3 & $7 / 27 / 2010$ & $8 / 23 / 2011$ & 391 & 68 & 22.2 & Transmitter removed, snake released \\
\hline 31 & $0^{7}$ & Yes & 0 & $8 / 5 / 2010$ & $9 / 27 / 2011$ & 423 & 62 & 23.1 & Lost-suspected transmitter failure ${ }^{c}$ \\
\hline 32 & $\sigma^{7}$ & Yes & 4 & $9 / 29 / 2010$ & $9 / 19 / 2011$ & 357 & 53 & & Lost-suspected death by human action \\
\hline 33 & $\sigma^{7}$ & Yes & 2 & $11 / 3 / 2010$ & $10 / 24 / 2011$ & 356 & 54 & 21.7 & Transmitter removed, snake released \\
\hline
\end{tabular}

${ }^{a}$ Indicates an LDT snake tracked previously as an SDT snake. ${ }^{\mathrm{b}}$ Snake initially translocated $519 \mathrm{~m}$, but erratic movement patterns suggested translocation beyond the normal home range of females, so reassigned to the LDT group. ${ }^{\mathrm{c}}$ Transmitter failure suspected when a deteriorating signal was lost and circumstances did not suggest another cause. ${ }^{d}$ Depredation suspected when the transmitter was found on the ground with no remains of snake nearby and no tooth marks on the transmitter. 


\subsection{Activity Range and Movements}

We used $\mathrm{R}$ version 4.1.1 [72] and the package adehabitatHR version 0.4.19 [73] to calculate the activity area and movement parameters. Because we deliberately attempted to move LDT snakes outside of their normal home ranges and non-LDT snakes may have been moved outside their normal home ranges, we used the more generalized term "activity area" to describe space utilization. We used the calendar year for between-year comparisons, because the snakes became inactive during December and January. We calculated two activity area statistics for each snake for each calendar year of tracking: 100\% minimum convex polygon (MCP) to facilitate comparison with previous studies and local convex hull $(\mathrm{LCH})$ via the "adaptive sphere of influence" calculation [74,75]. We further derived the mean daily movement (MDM) by dividing the distance moved between consecutive fixes by the number of days between fixes [76]. Since the number of location fixes affected the activity area estimates, we conducted a bootstrap analysis (10 randomly selected activity areas resampled 100 times each) to determine the minimum number of fixes needed for reliable estimates. Visual assessment of the bootstrapped curves suggested the need for at least 20 fixes.

For each location fix obtained for each snake, we calculated the distance to the nearest area with significant human modification (SHM). These areas were defined by the presence of buildings, roads, and well-maintained gardens and lawns (Figure 1). Areas subject to a lesser degree of human modification, such as plowed firebreaks and dirt trails, were not included. We obtained the UTM coordinates from Google Earth software (Google Inc., Mountain View, CA, USA) and calculated the Euclidean distances using R software.

\subsection{Statistical Analyses}

Because of legal constraints, only two snakes experienced no translocations, and many snakes experienced multiple SDTs. We therefore structured most of our analyses to include two groups of snakes-LDT and non-LDT-and treated the number of SDTs as a covariate.

\subsubsection{Activity Area and Mean Daily Movement}

We relied on linear mixed models (LMMs) to analyze the effects of LDT and SDT on activity areas and MDMs. Analyses were conducted using Jamovi 2.0.0 (The Jamovi Project, https: / / www.jamovi.org; accessed 9 February 2022) and the GAMLj library [77] with alpha set to 0.05 . The GAMLj library calculated the marginal and conditional $R^{2}$ for mixed models. The marginal $R^{2}$ measures the variance explained by fixed factors and the conditional $R^{2}$ measures the variance explained by both fixed and random factors [78]. Prior to model fitting, data exploration was carried out following the protocol suggested by [79]. All models included sex and year as fixed factors and the number of SDTs and SVL as covariates. To account for activity area calculations of the same snake between years, we used snake identity as a random intercept in each model. Because of the relatively small sample sizes, we exercised care in choosing the interaction terms to include in the model. To maintain statistical power and minimize overfitting, we did not consider three-way or greater interactions, and only included two-way interactions if we found support for them in visualizations created during data exploration. As is common when using smaller datasets, two models showed a singular fit, which can sometimes indicate overfitting. However, such models can also be well defined and theoretically sensible [80]. Since our singular models generated results that largely agreed with the results from our other, non-singular models, we report them here.

We developed two sets of LMMs. The first set considered only the effect of the number of SDTs on non-LDT snakes. It included data from all years (2008-2011) and comprised three separate models with 100\% MCP, 100\% LCH, and MDM as the dependent variables in their respective models and the independent variables mentioned above (sex, year, SDTs, and SVL). The two-way interactions of sex $\times$ year and sex $\times$ SVL were also included. The second set of LMMs considered the effects of both LDT and SDTs on the activity ranges and movements. These models included both LDT and non-LDT snakes, but the data were 
limited to 2010 and 2011, because no LDT snakes were added to the study in 2008 and the two snakes assigned to the LDT group in late 2009 had insufficient location fixes (minimum of 20) to be included for that year. This second set of models also used the same dependent and independent variables as the first set, but included LDT (versus non-LDT) as a fixed factor and the interaction terms LDT $\times$ year and sex $\times$ SVL. We computed the estimated marginal means to characterize group differences.

\subsubsection{Snake Mass and Mortality}

To assess the effect of snake translocation on the body condition of recaptured snakes, we calculated the percent change between the initial and last recorded measures of mass. We used analysis of covariance (ANCOVA) with SPSS v. 23 (Statistical Package for the Social Sciences, Inc., Chicago, IL, USA) to test the effects of sex, LDT versus non-LDT groups, and the number of SDT translocations (covariate) on the percent change in mass, which was log natural-transformed to address positive skew and heteroscedasticity after adding a constant to make all values positive. We confirmed the homogenous regression slopes prior to analysis and computed partial eta-squared $\left(\eta^{2}\right)$ as effect sizes.

We used survival analysis to examine snake mortality using $R$ and the survival package version 3.2-11 [81]. We analyzed the data both considering and omitting human-associated mortalities. We calculated the survival rates using the Kaplan-Meier procedure [82] following Pollock et al. [83] and the guidelines of Robertson and Westbrooke [84]. The time period used in these calculations was the total number of days the snake was tracked. Tracking began when the snake was released into the field after transmitter implantation and ended upon the last fix obtained for the snake, whether at the end of the study, when found dead in the field, or when found ill in the field and subsequently taken into captivity. The number of days a snake was held in captivity for surgery or recovery was subtracted from the time period. Two snakes that died following surgical complications were excluded from this analysis. To examine the effect of translocation on mortality, we developed a Cox proportional hazard model [85] that included both the translocation group as a fixed factor and the number of SDTs as a covariate.

\subsubsection{Risk of Human Conflict and Return to Capture Site after Translocation}

We also utilized Cox proportional hazards models to address two questions related to the potential for renewed conflict with humans subsequent to translocation: does translocation affect (1) whether a snake returns to areas of potential human conflict and (2) whether it returns to areas near its original captured site?

To assess the first question (returning to the SHM area), we used a model that included the snake sex and translocation group as factors, and the distance from each snake's initial release point to the nearest SHM area as a covariate. The time period used as the dependent variable began when the snake was released subsequent to transmitter implantation and ended the first time that snake moved within $50 \mathrm{~m}$ of any SHM area, or upon the last fix obtained for the snake, whether at the end of the study, when found dead in the field, or when found ill in the field and subsequently taken into captivity. For snakes lost due to a presumed transmitter failure, the final date was calculated as the midpoint between the last fix and the subsequent date when looked for, but not found [86].

To assess the second question (returning near the original capture site), our model again treated the sex and translocation group as fixed factors, but this time we used the first SDT distance as the covariate. Only snakes that underwent at least one SDT from an area $<50 \mathrm{~m}$ from an SHM area were used in this analysis, and only the first such event was considered to avoid pseudoreplication. This meant that the initial translocation of all snakes that underwent SDT immediately after transmitter implantation was included. Snakes in the LDT group or snakes that were not translocated after transmitter implantation were included if, subsequent to initial release, they moved into SHM areas and were then subjected to SDT. In such cases, only the first SDT event was included. We did not include the initial LDTs of those snakes in the LDT group in this analysis because, for several 
snakes in this group, the position of the SHM areas (i.e., residential development) blocked or would have significantly impeded their return to their original capture location in a large part because our protocol required that snakes moving into such areas be translocated back to areas they had been observed previously. The time period for this analysis began when the snake was released after SDT and ended when the snake returned within $50 \mathrm{~m}$ of the point it was translocated from or to the final location fix for that snake in the study, as defined above.

Since Cox proportional hazard models have few underlying assumptions [87], no transformations were applied to the data for any such analysis. We assessed the assumption of proportional hazard by using the proportional hazards test described by [88], as implemented in the survival package for R.

\section{Results}

A total of 30 adult C. ruber provided telemetry data at various periods of time between the middle of 2008 and the end of 2011. Because two of these snakes (snakes 2 and 11) were originally tracked as non-LDT, but were later re-assigned to the LDT group (becoming snakes 2.1 and 11.1; see above), our total sample size for the analyses was 32 (Table 1). The median number of days tracked for these snakes was 387.5 days (range: 11-1148), and a location fix was obtained for each of these snakes on average $( \pm S D)$ every $5.6 \pm 3.1$ days. Of these snakes, 22 were placed in the non-LDT (SDT + NT) group (11 males and 11 females) and 10 were classed as LDT snakes (7 males and 3 females). Snakes returning to SHM areas were subjected to as many as 14 SDTs. Pooled location fixes (Figure 1) revealed that snakes were always found in areas with cover and avoided open areas, such as plowed fire breaks.

\subsection{Activity Ranges and Movements}

The results of the linear mixed models that included data from all years, but excluded LDT snakes, are shown in Table 2. These models provided mixed results for the effect of SDTs on activity areas. The model for $100 \% \mathrm{MCP}$, as the estimate for activity area, suggested that number of SDTs increased the activity range size (estimate $=0.56,95 \% \mathrm{CI}$ : $0.12-1.01, p=0.022$ ), whereas the model for $100 \%$ LCH did not (estimate $=-0.14,95 \%$ CI: $-0.34-0.07, p=0.22)$. The model that included MDM also showed a significant and direct effect of SDTs on snake movement (estimate $=1.93,95 \%$ CI: $-0.96-2.89, p<0.001$ ). These models further suggested that sex influenced the activity area. The model using $100 \% \mathrm{LCH}$ showed a direct effect of sex, with males having activity areas averaging 1.25 ha $(186.5 \%)$ larger than females, when holding other variables constant (estimate $=1.25,95 \%$ CI: $0.51-1.99, p=0.005)$. Although the $100 \%$ MCP model did not show a primary effect of sex (estimate $=1.06,95 \% \mathrm{CI}:-0.45-2.57, p=0.19$ ), the significant interaction between sex and SVL (estimate $=0.12,95 \%$ CI: $0.02-0.22, p=0.033$ ) suggested that the male activity areas increased with SVL, whereas those of females remained relatively constant (Figure 2).

Table 2. Results of three linear mixed models examining the effects of the number of short-distance translocations (SDTs), sex, year, and snout-vent length (SVL) on activity ranges $(100 \%$ minimum convex polygon (MCP) and 100\% local convex hull (LCH)) and mean daily movements (MDM) of radiotransmittered adult Red Diamond Rattlesnakes (Crotalus ruber) during 2008-2011.

\begin{tabular}{|c|c|c|c|c|c|c|c|c|c|c|c|c|}
\hline & \multicolumn{4}{|c|}{$100 \% \mathrm{MCP}$} & \multicolumn{4}{|c|}{$100 \% \mathrm{LCH}$} & \multicolumn{4}{|c|}{ MDM } \\
\hline & $F$ & Num df & Den df & $p$ & $F$ & Num df & Den df & $p$ & $F$ & Num df & Den df & $p$ \\
\hline SDTs & 6.24 & 1 & 18.41 & 0.022 & 0.09 & 1 & 25.00 & 0.770 & 15.31 & 1 & 19.60 & $<0001$ \\
\hline Sex & 1.90 & 1 & 15.69 & 0.187 & 5.66 & 1 & 25.00 & 0.025 & 0.01 & 1 & 16.99 & 0.927 \\
\hline Year & 4.01 & 3 & 18.18 & 0.024 & 3.13 & 3 & 25.00 & 0.044 & 1.26 & 3 & 19.22 & 0.316 \\
\hline SVL & 7.42 & 1 & 12.04 & 0.018 & 6.25 & 1 & 25.00 & 0.019 & 0.90 & 1 & 13.44 & 0.359 \\
\hline Sex $\times$ Year & 1.48 & 3 & 19.34 & 0.252 & 2.11 & 3 & 25.00 & 0.125 & 0.78 & 3 & 20.24 & 0.518 \\
\hline Sex $\times$ SVL & 5.72 & 1 & 12.97 & 0.033 & 2.67 & 1 & 25.00 & 0.115 & 1.84 & 1 & 14.39 & 0.196 \\
\hline$R^{2}$ Marginal & \multirow{2}{*}{\multicolumn{4}{|c|}{0.61}} & \multicolumn{4}{|c|}{0.55} & \multicolumn{4}{|c|}{0.52} \\
\hline$R^{2}$ Conditional & & & & & \multicolumn{4}{|c|}{0.55} & \multicolumn{4}{|c|}{0.54} \\
\hline
\end{tabular}




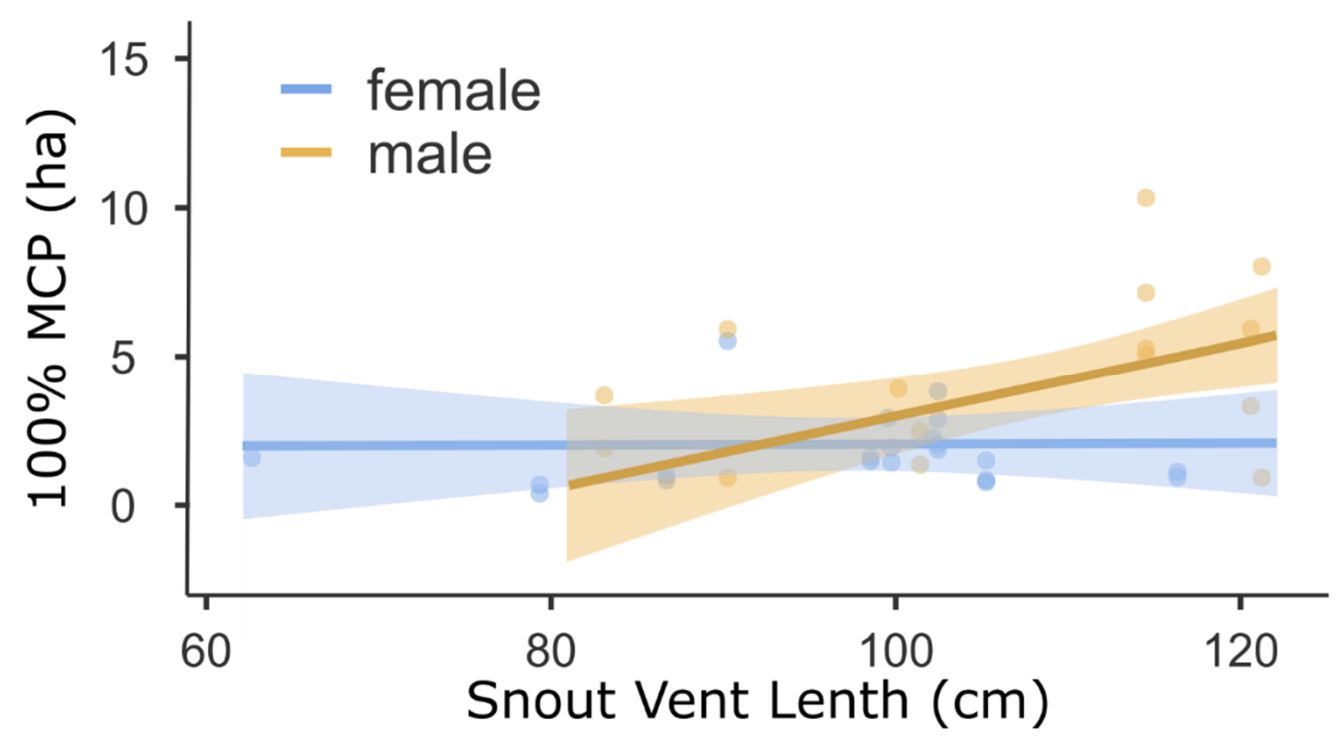

Figure 2. Model-adjusted relationships between snout-vent length and the $100 \%$ minimum convex polygon (MCP) activity area estimates for adult male $(n=7)$ and female $(n=11)$ Red Diamond Rattlesnakes (Crotalus ruber) that did not undergo long-distance translocation in Loma Linda, California. The $95 \% \mathrm{CI}$ is shown around the trend lines.

The 100\% LCH model also showed a significant and direct effect of SVL (estimate $=0.06$, 95\% CI: $0.02-0.11, p=0.018$ ). The year was significant in both the $100 \% \mathrm{MCP}$ and $100 \%$ LCH models, with marginal means suggesting larger activity areas in 2009 compared to the other years, but with no obvious relationship involving precipitation (Figure 3) and despite the higher proportion of females (Table 2 footnote) tracked that year. For MDM, however, year exerted no significant effect.

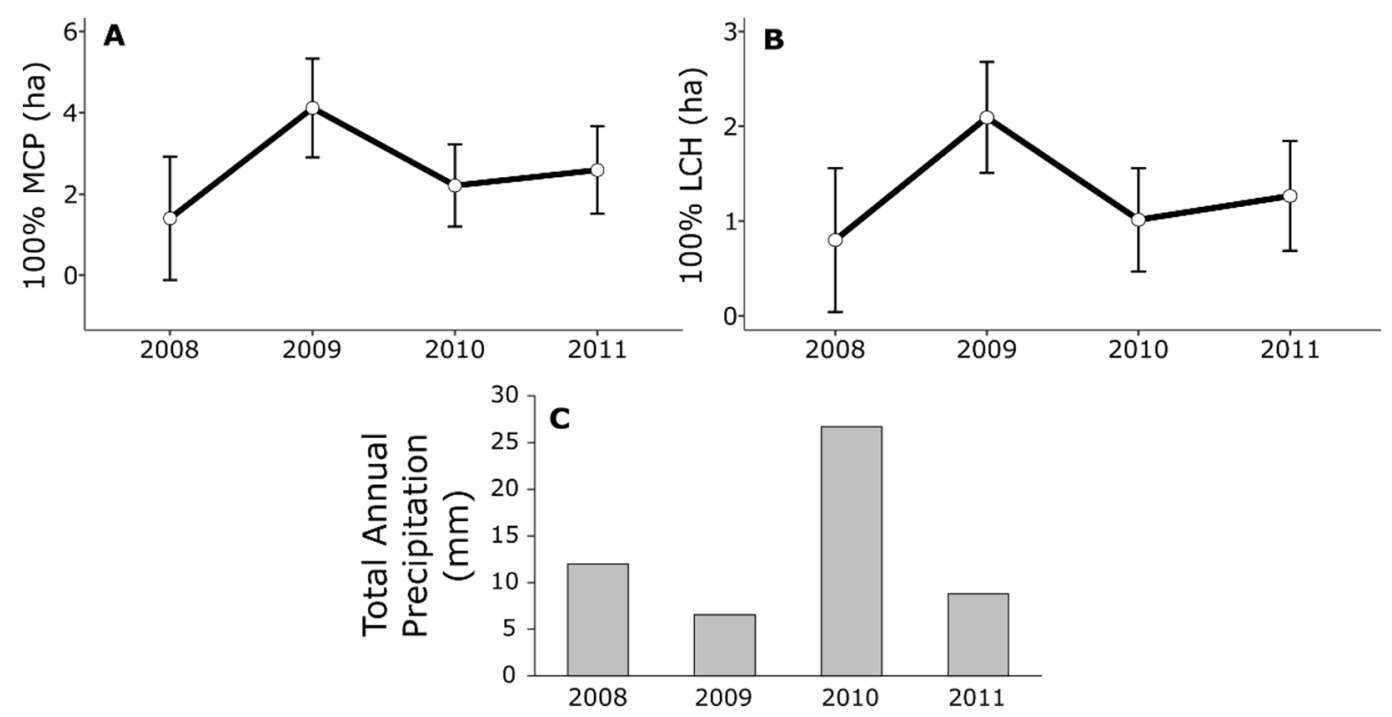

Figure 3. Estimated marginal means $( \pm 95 \% \mathrm{CI})$ from the linear mixed models showing the activity areas per year as estimated using the (A) 100\% minimum convex polygon (MCP) and (B) $100 \%$ local convex hull (LCH) for adult Red Diamond Rattlesnakes (Crotalus ruber) in Loma Linda, California. $n=6,11,10$, and 9, for 2008-2011, respectively. (C) Total precipitation, reflecting long-term drought, from the National Centers for Environmental Information weather station in the nearby Redlands, California, where the mean precipitation is $34.4 \mathrm{~cm}$ [67].

The results of the linear mixed models that considered LDT snakes, the number of SDTs, and only data from 2010 and 2011 revealed a clear effect of translocation type (LDT vs. 
non-LDT), especially in relation to the interaction with year (Table 3). All three models with the dependent measures 100\% MCP, 100\% LCH, and MDM showed this interaction to be significant (respective estimates $=7.55,95 \%$ CI: 3.42-11.68, $p=0.001 ; 2.43,95 \%$ CI: 0.41-4.45, $p=0.036$; and 8.64, 95\% CI: 3.00-14.28, $p=0.009)$. Examination of the marginal means (Figure 4) indicated that, in the year LDT snakes were added to the study (2010), LDT snakes had activity areas $4.58(100 \% \mathrm{MCP})$ and $3.47(100 \% \mathrm{LCH})$ times larger than those of non-LDT snakes. The MDM distances were also 1.84 times larger in LDT snakes. However, these differences disappeared in the following year (2011). These models also provided mixed results regarding the effects of SDT on activity areas and MDM. The number of SDTs showed no significant effect on 100\% MCP (estimate $=0.30,95 \%$ CI: $-0.05-0.64$, $p=0.10$ ), but was nearly significant for $100 \% \mathrm{LCH}$ (estimate $=0.18,95 \%$ CI: $0.01-0.36$, $p=0.052$ ). The effect of SDTs was significant and directly related to MDM (estimate $=0.76$, 95\% CI: $0.25-1.27, p=0.007)$. Unlike the previous models, all models showed a significant effect of sex (100\% MCP: estimate $=3.00,95 \%$ CI 0.89-5.12, $p=0.010 ; 100 \%$ LCH: estimate $=1.31,95 \%$ CI 0.20-2.42, $p=0.047 ;$ MDM: estimate $=6.24,95 \%$ CI 2.91-9.58, $p=0.004$ ), with males exhibiting larger activity areas and greater MDM than females, with males averaging 3.00 ha $(82.6 \%)$ larger for $100 \% \mathrm{MCP}, 1.31$ ha $(98.5 \%)$ larger for $100 \% \mathrm{LCH}$, and $6.24 \mathrm{~m} / \mathrm{d}(88.9 \%)$ larger for MDM.

Table 3. Results of the omnibus tests from three linear mixed models examining the effects of longdistance translocation (LDT vs. non-LDT), the number of short-distance translocations (SDTs), sex, year, and snout-vent length (SVL) on the activity ranges (100\% minimum convex polygon (MCP) and $100 \%$ local convex hull (LCH)) and mean daily movements (MDM) of adult Crotalus ruber during 2010 and 2011.

\begin{tabular}{|c|c|c|c|c|c|c|c|c|c|c|c|c|}
\hline & \multicolumn{4}{|c|}{$100 \% \mathrm{MCP}$} & \multicolumn{4}{|c|}{$100 \% \mathrm{LCH}$} & \multicolumn{4}{|c|}{ MDM } \\
\hline & $F$ & Num df & Den df & $p$ & $F$ & Num df & Den df & $p$ & $F$ & Num df & Den df & $p$ \\
\hline LDT & 21.28 & 1 & 25.00 & $<0.001$ & 7.17 & 1 & 9.14 & 0.025 & 3.07 & 1 & 11.62 & 0.106 \\
\hline SDTs & 2.90 & 1 & 25.00 & 0.101 & 5.39 & 1 & 8.35 & 0.052 & 13.46 & 1 & 10.77 & 0.007 \\
\hline Sex & 7.74 & 1 & 25.00 & 0.010 & 3.72 & 1 & 12.33 & 0.047 & 9.12 & 1 & 14.41 & 0.004 \\
\hline Year & 10.51 & 1 & 25.00 & 0.003 & 0.13 & 1 & 8.57 & 0.077 & 0.03 & 1 & 11.00 & 0.009 \\
\hline SVL & 0.27 & 1 & 25.00 & 0.608 & 4.17 & 1 & 24.02 & 0.727 & 8.64 & 1 & 24.69 & 0.856 \\
\hline LDT $\times$ Year & 12.82 & 1 & 25.00 & 0.001 & 5.58 & 1 & 12.25 & 0.036 & 9.02 & 1 & 14.33 & 0.009 \\
\hline Sex $\times$ SVL & 0.37 & 1 & 25.00 & 0.547 & 0.55 & 1 & 9.12 & 0.475 & 0.54 & 1 & 11.61 & 0.477 \\
\hline$R^{2}$ marginal & \multicolumn{4}{|c|}{0.64} & \multicolumn{4}{|c|}{0.47} & \multicolumn{4}{|c|}{0.59} \\
\hline$R^{2}$ conditional & \multicolumn{4}{|c|}{0.64} & \multicolumn{4}{|c|}{0.52} & \multicolumn{4}{|c|}{0.66} \\
\hline
\end{tabular}

Significant $p$-values are shown in bold. Sample sizes: 7 LDT and 6 non-LDT males, 2 LDT and 6 non-LDT females (2010); 7 LDT and 5 non-LDT males, 2 LDT and 4 non-LDT females (2011).

\subsection{Snake Mass and Mortality}

We measured the change in mass of 19 recaptured snakes (including both sampling periods for snake 11). The body mass change ranged from $35.2 \%$ loss to $100.9 \%$ gain (Table 1). Thirteen $(68.4 \%)$ of the 19 individuals gained mass, including 10 of 12 males and 3 of 7 females (Table 1). The ANCOVA model revealed no difference in the percent mass change between the sexes (mean \pm SE: males $18.6 \% \pm 8.5 \%$ gain, $n=12$; females $3.1 \% \pm 10.4 \%$ loss, $n=7 ; F_{1,14}=0.32, p=0.58$, partial $\left.\eta^{2}=0.02\right)$, no difference between LDT groups (LDT $17.7 \% \pm 4.0 \%$ gain, $n=12$; non-LDT $6.5 \% \pm 10.6 \%$ gain, $n=7 ; F_{1,14}=0.96$, $p=0.34$, partial $\eta^{2}=0.06$ ), no effect of the number of SDTs (range $0-16 ; F_{1,14}=0.65, p=0.43$, partial $\left.\eta^{2}=0.05\right)$, and no interaction between sex and LDT group $\left(F_{1,14}=0.66, p=0.43\right.$, partial $\left.\eta^{2}=0.05\right)$. All effect sizes were similarly small. 


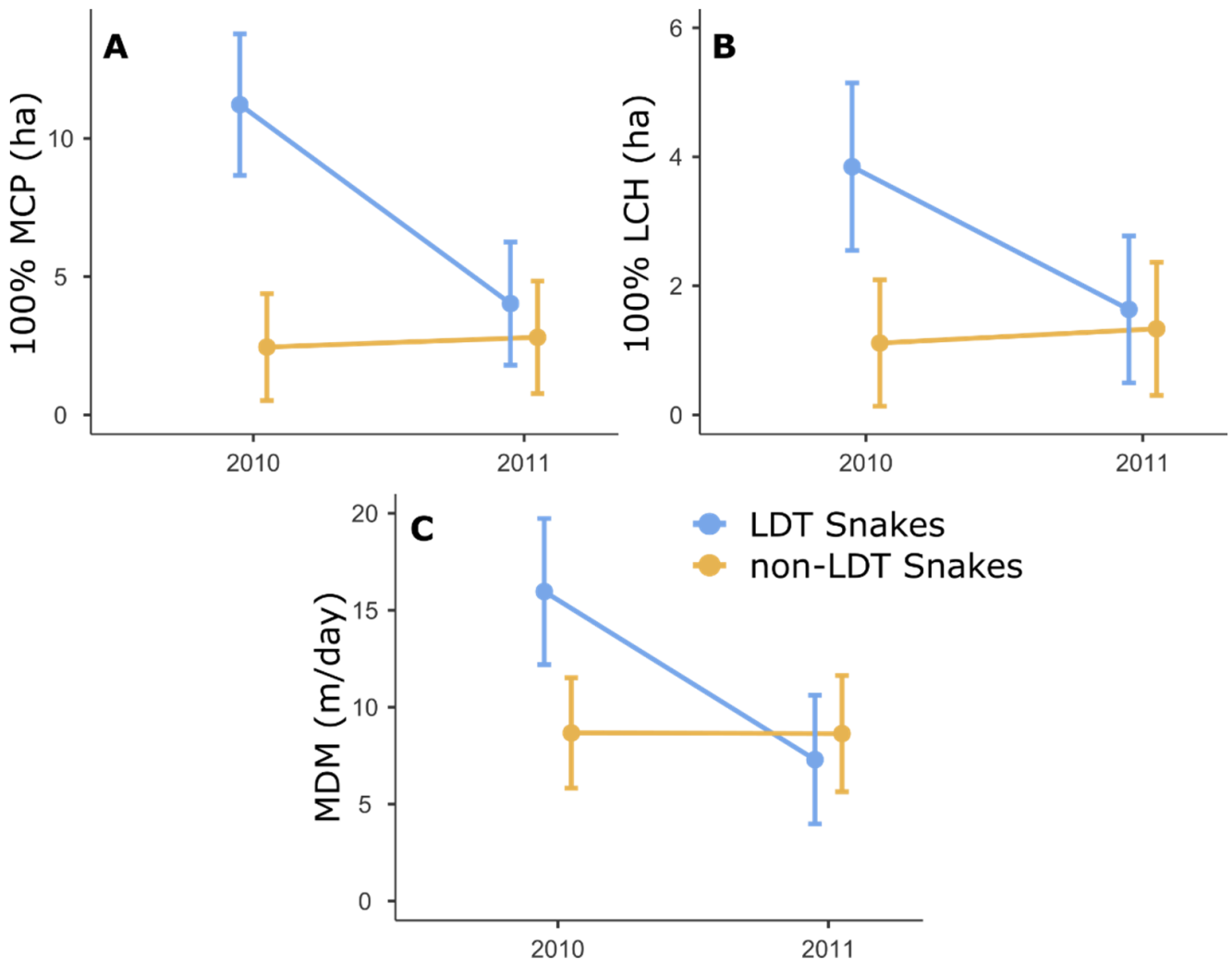

Figure 4. Estimated marginal means $( \pm 95 \% \mathrm{CI})$ from the linear mixed models showing the interaction of long-distance translocation (LDT) and year on the activity area as estimated using the (A) 100\% minimum convex polygon (MCP) and (B) 100\% local convex hull (LCH), and (C) mean daily movement (MDM) for adult Red Diamond Rattlesnakes (Crotalus ruber) in Loma Linda, California. $n=6$ LDT and 10 non-LDT in 2010, and 8 LDT and 9 non-LDT in 2011. Snakes subjected to LDT in 2010 exhibited greater activity areas and movements than in 2011.

Based on the available evidence, we determined that nine deaths occurred during the study (Table 1). Two events resulted from complications associated with surgery. One of these two (snake 5) died during transmitter replacement surgery. The other (snake 10) was tracked for 88 days, but then sustained an injury that reopened the surgical incision and caused tearing, exposing a large portion of the coelomic cavity. The snake died four days later in our laboratory, despite our best efforts to disinfect and close the wound. Of the seven remaining deaths, we attributed two to predation. We found the transmitter of snake 4 on open ground with unambiguous bite marks, and near a portion of the snake's rattle containing the painted segments used for identification. We found the transmitter of snake 14 on the ground with probable bite marks, but without snake remains nearby. We attributed three deaths to the action of humans. We found the decapitated body of snake 2.1 in a plowed firebreak area $30 \mathrm{~m}$ from a home and a private tennis court. The clean nature of the decapitation wound and absence of injury to the remaining body suggested that a sharp object was used followed by burial of the head, which was not found. Snake 20 was buried by heavy earthmoving equipment as part of a landscaping project to expand the cemetery in the western portion of the study site. We confirmed this death by digging up the snake's remains. A third presumed case of human-caused mortality resulted when snake 32, observed in a large pile of brush and rocks within the area of the cemetery landscaping project nine days after SDT away from the same landscaping project, disappeared after the pile was loaded by heavy equipment into large dumpsters and hauled away. In the remaining two cases of death, one resulted from apparent disease and the other from unknown causes. We found snake 17 writhing and biting the ground in an area of coastal sage scrub, and subsequently euthanized the snake when it deteriorated further in our lab. 
We found the transmitter of snake 22 devoid of marks and in a large brush pile $24 \mathrm{~m}$ from a house, suggesting either predation or human-caused death. A summary of first-year survival is shown in Table 4.

Table 4. Summary of first-year survival ( $\leq 365$ days of tracking) for adult Crotalus ruber that were either long-distance translocated (LDT) or not (non-LDT). Survival rate excludes snakes lost during the study from presumed transmitter failure and one snake that died of surgical complications during the first year of tracking.

\begin{tabular}{cccccc}
\hline Group & N & Survived (\%) & Lost (\%) & $\begin{array}{c}\text { Confirmed } \\
\text { Dead (\%) }\end{array}$ & $\begin{array}{c}\text { Survival } \\
\text { Rate (\%) }\end{array}$ \\
\hline $\begin{array}{c}\text { Without Human Mortality } \\
\text { Non-LDT }\end{array}$ & 21 & 61.9 & 28.6 & 9.5 & 86.7 \\
LDT & 9 & 88.9 & 11.1 & 0.0 & 100.0 \\
$\begin{array}{c}\text { With Human Mortality } \\
\text { Non-LDT }\end{array}$ & 21 & 61.9 & 28.6 & 9.5 & 86.7 \\
LDT & 10 & 80.0 & 10.0 & 10.0 & 88.9 \\
\hline
\end{tabular}

We tracked all snakes for a total of 13,616 days, which corresponded to 37.30 snake years. The minimum annual mortality based on snake years was $2.7 \%$ (one event) for disease, $5.4 \%$ (two events) for predation, and $8.0 \%$ (three events) for human-associated causes. Including the presumed predation/human-caused death of snake 22, the combined mortality for predation and human causes was $16.1 \%$ (six events) and the total annual mortality was $18.8 \%$ (seven events). These calculations excluded the two surgery-related deaths.

We conducted two survival analyses classifying each of the snakes above as ending in a mortality event. The first analysis included human associated deaths. The mean $( \pm$ SE) survival time for all snakes was $853 \pm 94$ days, with $857 \pm 139$ days for LDT snakes and $858 \pm 121$ days for non-LDT snakes. The mean survival time was $808 \pm 136$ days for males and $894 \pm 126$ days for females. Cox proportional hazard analysis failed to detect significant effects of LDT, sex, or number of SDTs on survival (LDT hazard ratio $(\mathrm{HR})=1.30,95 \% \mathrm{CI}=0.26-6.41, \mathrm{z}=0.32, p=0.75$; sex $\mathrm{HR}=1.04,95 \% \mathrm{CI}=0.21-5.15$, $\mathrm{z}=0.05, p=0.96$; SDTs HR $=0.95,95 \% \mathrm{CI}=0.79-1.14, \mathrm{z}=-0.52, p=0.61$ ). The second analysis excluded human associated deaths. For this analysis, the survival time for all snakes was $974 \pm 77$ days, with $1036 \pm 101$ days for LDT snakes versus $946 \pm 103$ days for non-LDT snakes, and $981 \pm 106$ days for males versus $962 \pm 116$ days for females. The Cox proportional hazard analysis for this group again failed to detect a significant effect of LDT, sex, or number of SDTs (LDT HR =0.54,95\% CI = 0.51-5.63, z = -0.52, $p=0.60$; $\operatorname{sex} \mathrm{HR}=1.06,95 \% \mathrm{CI}=0.13-8.68, \mathrm{z}=0.05, p=0.96$; SDTs HR $=1.00,95 \% \mathrm{CI}=0.80-1.26$, $\mathrm{z}=0.03, p=0.98)$.

\subsection{Risk of Return to Human-Modified Areas}

Following transmitter implantation, snakes (including those from both translocation groups) were initially released an average of $152.5 \mathrm{~m}$ (range: 25.9-459.5 m) away from the nearest SHM area. Omitting two snakes initially released $<50 \mathrm{~m}$ away from SHM areas, $73.3 \%$ of all snakes (22 out of 30 ), regardless of translocation group, moved to areas within $50 \mathrm{~m}$ of SHM areas subsequent to initial release. The median time for these snakes to move to these areas was 48 days $(95 \% \mathrm{CI}=19-261)$ based on a Kaplan-Meier analysis. Cox regression revealed that an increase in distance between a snake's release point and SHM area reduced the risk of a snake returning to such areas $(\mathrm{HR}=0.989,95 \% \mathrm{CI}=0.978-0.999$, $n=30, \mathrm{z}=-2.09, p=0.037)$. While holding other factors constant, every $1 \mathrm{~m}$ increase in distance from the release point to SHM areas decreased the risk of returning to such areas by $1.2 \%(95 \% \mathrm{CI}=0.1-2.2 \%)$. However, no difference was detected between the translocation groups $(\mathrm{HR}=95 \% \mathrm{CI}=0.59-3.67, n=30, \mathrm{z}=0.82, p=0.41)$ or sexes $(\mathrm{HR}=0.74$, $95 \% \mathrm{CI}=0.30-1.84, n=30, \mathrm{z}=-0.65, p=0.52)$. 


\subsection{Risk of Return to Area of Capture after Translocation}

Of the 22 snakes that experienced SDT away from SHM areas at some point during the study, the first such translocation for these snakes averaged ( \pm SD) $246.2 \pm 155.7 \mathrm{~m}$ (range 32.2-633.3 m). Omitting one snake that was translocated less than $50 \mathrm{~m}, 11$ of 21 $(52.4 \%)$ returned to within $50 \mathrm{~m}$ of their original location. The median time to return was 163 days (95\% CI = 31-no upper limit) based on Kaplan-Meier analysis. Cox regression again showed a small, but significant, effect of the distance the snake was translocated away from its capture site $(n=21, \mathrm{HR}=0.984,95 \% \mathrm{CI}=0.973-0.995, \mathrm{z}=-2.78, p=0.005)$. Keeping other variables constant, for every $1 \mathrm{~m}$ increase in the translocated distance, the risk of return decreased by $1.6 \%(95 \% \mathrm{CI}=0.5-2.7 \%)$. No differences existed between the translocation groups $(\mathrm{HR}=1.466,95 \% \mathrm{CI}=0.283-7.601, \mathrm{z}=0.46, p=0.65)$ or sexes $(\mathrm{HR}=0.367,95 \% \mathrm{CI}=0.086-1.567, \mathrm{z}=-1.35, p=0.18)$.

None of the 10 LDT snakes returned to within $50 \mathrm{~m}$ of their initial capture sites, except for the one female (snake 19) that was initially translocated $519 \mathrm{~m}$ on 13 October 2009 but was assigned to the LDT group due to its extensive and erratic movements after translocation. This snake returned to within $50 \mathrm{~m}$ of its initial capture site after 184 days. Another LDT snake (snake 33), translocated $2573 \mathrm{~m}$ from his initial capture site, appeared to make an effort to return. Subsequent to its initial release on 1 November 2010, this snake moved $681 \mathrm{~m}$ in a direction toward its capture site until 11 November 2010, when it moved into a residential area and on the grounds of an elementary school. It was then translocated $633 \mathrm{~m}$ back to its original translocated position. The snake again moved $618 \mathrm{~m}$ in a direction towards its capture site and returned to within $126 \mathrm{~m}$ of the same elementary school on 15 December 2010. At this point, to prevent the snake from returning to the elementary school, we broke protocol and again recaptured the snake prior to re-entering an area of potential human conflict (which is why this translocation was excluded from the translocation analysis above). We translocated this snake $582 \mathrm{~m}$ (straight-line distance) back to the point of its initial release. It then overwintered near this release point. The snake did not move in the direction of its capture location the following spring and was found paired with a female on 3 March 2011.

\section{Discussion}

Mitigation translocation has received increasing attention as an option for dealing with nuisance wildlife, including venomous snakes. However, three key concerns have been raised: (1) the potential of harm to the translocated snake; (2) return of the snake to the original site of human-snake conflict; and (3) population-level effects that result from the translocated animal. In this study, we used radiotelemetry to assess the effects of LDT and SDT on adult rattlesnakes to improve our understanding of the first two concerns. If translocation represents a successful management tool for reducing human-snake conflict, it should minimally impact the translocated snake while reducing the likelihood of the snake returning to a site of potential conflict. We sought to learn how the distance of nuisance snake translocation from SHM areas would impact their subsequent spatial ecology, movements, body condition, survival, and, ultimately, their potential for conflict with humans. Our method of analysis allowed us to draw useful conclusions, despite our study design being constrained by property owner requests and liability issues that compelled us to translocate all snakes initially found in SHM areas, and those that returned subsequently to these areas.

\subsection{Translocation Effects on the Snake}

One major concern about mitigation translocation is the potential for negative impacts on the snake. Previous studies suggest that translocated snakes are prone to wander and exhibit increased stress levels, which may ultimately lead to increased mortality (see Introduction). Consistent with these studies, we found evidence that both SDT and LDT increased the activity range size and mean daily movement. Although the results of our statistical models were mixed for the effect of SDTs, some of these models suggested 
an increase in activity range size of $0.18-0.56$ ha per SDT and an increase in MDM of 0.76-1.93 m per SDT. The effect of LDT (vs. non-LDT) was much clearer, with the models suggesting a 3.47-4.58-fold increase in the activity area and a 1.84-fold increase in MDM for LDT snakes compared to non-LDT snakes during their first year after translocation. However, our results also showed that the activity areas and MDMs of LDT snakes were similar to those of non-LDT snakes in the second year after translocation. The difference between years suggests that these snakes became acclimated to their new environment [59].

Our results further showed males occupying activity ranges 1.25-3.00 ha (82.6-186.5\%) larger than those of females, and moving up to $6.24 \mathrm{~m} / \mathrm{d}(88.9 \%)$ more than females. We expected these differences, as males of C. ruber elsewhere [49] and those of other rattlesnake species (e.g., [89-93]; but see [94]) exhibit greater levels of activity than females. Moreover, the activity range size increased with increasing SVL for male snakes, but not for female snakes. We did not detect or explicitly test interactions between sex and LDT or SDTs, but sex- and size-based differences may exist in the behavior of snakes translocated to unfamiliar surroundings and, ultimately, in their tolerance to LDT. Because males roam widely when searching for females, they may be equipped with behavioral and physiological adaptations that enable them to navigate and otherwise cope with being in previously unexplored areas, which females, who generally move much less and have smaller home ranges, may lack. The presence of such physiological adaptations has been suggested in several field studies $[28,61,62]$. Although only male rattlesnakes were used in the studies, snakes repeatedly subjected to SDT developed larger medial cortexes than the controls, presumably in response to increased navigational demands [61,62], and the increased testosterone levels in LDT snakes may aid in spatial learning and memory [28]. The studies further found no differences in the levels of the stress hormone corticosterone between translocated and control snakes. If males are adapted to cope with unfamiliar areas, then such a reduced stress response would be expected.

Although our snakes exhibited increases in space use and movements due to both LDT and SDTs, the changes in body condition and survival (overall and during the first year) were similar between the sexes, between LDT and non-LDT snakes, and unaffected by the number of SDTs. Prior research has shown no differences in mortality for SDT snakes compared with controls [49,50,60-62]. For LDT snakes, however, previous studies offer mixed conclusions. Brown et al. [49] did not detect a difference in mortality between LDT and non-translocated C. ruber, but other studies of C. atrox and C. horridus reported that LDT snakes suffered higher mortality [48,59]. (Another study [28] observed no mortality in both control and LDT snakes, but the study duration was only one month.) The difference between $C$. ruber and other species may be due to differences in habitat and/or dependence upon specific hibernacula for overwinter survival. In cooler climates, snakes unable to find suitable locations to hibernate ( $\approx$ brumate) are much less likely to survive the winter [37]. Indeed, a significant number of mortalities among LDT snakes of $C$. horridus [59] occurred during the winter, and high winter mortality was reported in repatriated Massasuaga rattlesnakes (Sistrurus catanatus) [54,56]. In warmer climates, such as lower elevations in southern California, the need to utilize specific or communal hibernacula to escape freezing conditions is reduced or absent $[64,95]$, and hence overwintering may have less of an effect on survival.

Regardless of translocation experience, our study subjects experienced human-associated mortality $(8.0 \%$ /year) at the same rate as natural causes $(2.7 \%$ for disease, $5.4 \%$ for predation, $8.0 \%$ combined). Without the agreements in place with property owners and our Herculean translocation efforts (122 translocations away from SHM areas), these snakes would likely have experienced substantially higher mortality. Clearly, snakes at the suburbanwildlands interface suffer inevitably high risks of mortality.

\subsection{Risks Associated with Human-Snake Conflict}

The second major concern of mitigation translocation is whether the snake is less likely to return to the area of potential human-snake conflict. We considered two measures of 
potential conflict in relation to snake translocation: (1) whether snakes returned to SHM areas in general, and (2) whether snakes returned to the areas near their original capture sites. Prior studies of snake translocation have only considered the latter measure.

A high proportion (73.3\% of 30 ) of snakes moved near SHM areas at some point during the study (median of $48 \mathrm{~d}$ after initial release), and roughly half of those translocated a short distance away from SHM areas (52.4\% of 22) returned to within $50 \mathrm{~m}$ of their original capture site in an SHM area (median of 163 days). The probability of return to either SHM areas or the original capture site did not differ among translocation groups or sexes. Some snakes in all groups were subjected to SDTs, so the lack of differences between translocation groups seems expected. However, the risk of a snake moving to an SHM area or returning to the original site of capture decreased by approximately $1.2 \%$ and $1.6 \%$, respectively, per $1 \mathrm{~m}$ translocated distance. Clearly, the capacity of translocation to reduce conflict depends on the distance a snake is moved from the location of conflict.

Snakes subjected to LDT may nevertheless experience negative impacts. Such individuals may take time to orient themselves to the new environment and, as a result, increase their movements and exposure to risks as they search for suitable areas to forage, bask, shelter, and locate mates. If these snakes exhibit natal habitat preference induction and have established natal home ranges that include SHM areas, then such snakes may seek such areas once translocated, and either come into conflict with humans again, or move into sub-optimal habitats that the snake perceives to be similar to SHM areas, and thereby increase their risk of mortality [96].

\subsection{Implications for Managing Nuisance Rattlesnakes}

Those who deal with human-wildlife conflict must take into consideration the three aforementioned issues when mitigating situations involving nuisance animals. Our research has addressed the first two issues for rattlesnakes, which include the potential negative impact to the individual nuisance animal and the risk to humans (or property) posed by a returning animal. The third issue is the potential negative impact to the population the animal is a part of and/or the population it may be moved to if translocated. We will comment on each of these as they relate to managing nuisance rattlesnakes.

With regard to the welfare of the nuisance animal, there are three major options for dealing with nuisance rattlesnakes: (1) leaving the snake alone, which a property owner often objects to; (2) euthanasia, which has the most deleterious impact to the snake and is therefore considered least humane; or (3) removal of the live snake, either by translocating it to another area or maintaining it indefinitely in captivity. For translocation, a trade-off exists between immediate effects on the snake's behavior, including an increased risk of death (the major problem with LDT), versus future return to the area of conflict (the major problem with SDT), which could result once again in human conflict and the death of the snake. Long-distance translocation has been strongly criticized as a strategy that unacceptably increases the probability of snake death (e.g., $[13,48,59])$. However, two studies of $C$. ruber (ours and [49]) suggest that LDT can be a viable option for at least some species, or for snakes in certain climates or habitats. Much of the mortality reported for translocated snakes of other species has been associated with brumation $\approx$ hibernation [56,59], often at communal hibernacula. Repatriated snakes (captive-raised prior to release in the wild) have similarly been especially vulnerable during the hibernation period [54]. The milder climate of southern California, where many snakes overwinter individually without strong site fidelity $[64,95]$, may reduce the risk of overwintering mortality in translocated snakes. Other factors no doubt contribute to translocation success, including the species' biology (C. ruber is a relatively sedentary species [64]), snake population density, and availability of prey and refugia. At present, we find no compelling evidence to recommend against LDT in the southern California region, except at higher altitudes where communal overwintering at scarcely distributed suitable sites may be critical for survival. Nevertheless, we certainly agree with others (e.g., $[13,18,97-99])$ that public education about tolerating nuisance rattlesnakes would be a viable alternative or supplement to mitigation translocation. 
Although LDT may increase the probability of rattlesnake mortality in the short term, at least the snakes are given a chance to succeed. Some consider the reduced survival rate of LDT unacceptable (e.g., [13,59]); however, all wild snakes will experience death eventually through illness, starvation, depredation, and/or senescence, any of which might cause equal levels of suffering [100]. Many LDT snakes live beyond the first year of highest vulnerability, and thereafter may thrive as successfully as non-translocated snakes [59]. We see no reason why LDT would be more unethical than euthanasia, particularly in areas where SDT or tolerance are not suitable options for property owners.

With regard to the risk of the nuisance animal to humans or property, venomous snakes actually pose a very low risk to humans in the United States. Recent estimates put the incidence of snake envenoming at 0.79 per 100,000 per year and the incidence of death at 0.001 per 100,000 per year [40]. Certainly, the risk is higher for those who live in more rural areas, those who spend significant time in natural areas for recreational or occupational purposes, and those whose health may be somewhat compromised. Yet, in many cases, human envenomation occurs because a human deliberately chooses to interact with the snake-either to harass, kill, or capture it—suggesting that the risk of envenomation would be significantly reduced if people would simply choose to leave the snake alone.

Although no research has examined the third issue for rattlesnakes, strategies for mitigating human-wildlife conflict can be expected to exert effects at the population level $[11,13,16,34,35]$. Certainly, indiscriminate use of euthanasia has the potential to deplete local populations - an outcome that can be particularly undesirable if the species in question is protected, as in our study, or is a high-trophic-level consumer (i.e., predator), which can lead potentially to profound ecosystem change [13,45,46]. Moreover, euthanasia may alter sex ratios by affecting one sex more than the other. Previous studies indicate a male bias in snake mortality caused by humans [101,102], and male rattlesnakes may be responsible for more human envenomations than females [103], suggesting that males may be more likely to come into conflict with humans.

Translocations involving substantial distance have the potential to affect both the source population (assuming an absence of homing to the original location) and the population the animal is moved to. For rattlesnakes, LDT beyond the typical home range, but within a few kilometers beyond it, involves distances too limited to affect anything more than the immediate neighbors of the translocated snake. Given the dynamic nature of snake home ranges, which contract and expand seasonally and from year to year, and generally overlap widely the ranges of other snakes [104], any impacts from the translocation of a few snakes should be fairly negligible. More problematic would be the removal of an excess number of snakes from a given location, as the local population could suffer predator depletion. Sex ratios might also become skewed in both the source (female-biased, with the removal of more males) and receiving (male-biased) populations. These risks are not only dependent on the distance these snakes are moved, but also on the number of animals moved. Nuisance snake dumping involving dozens of individuals at the same location has been described in Arizona [38], and no doubt has negative repercussions for the dumped snakes and the local environment. With regional translocation beyond the local deme, the translocated snake may become a vector of disease transmission to the receiving population, alter the genetic structure of the receiving population, or increase the receiving population beyond its carrying capacity [11,45]. For rattlesnakes, the consequences of translocation into currently unoccupied areas or beyond the species' range have not been examined, but there are compelling reasons to recommend against this practice, unless it is part of a carefully monitored repatriation program ([56] and references therein).

\section{Conclusions}

This study investigated nuisance snake translocation as a management tool for reducing human-snake conflict. Although rattlesnakes translocated beyond their normal home range exhibited increased space use and movements, those moved greater distances from human-modified areas were less likely to return, and they experienced survival rates 
similar to those moved short distances. Thus, our findings add to the growing body of evidence that translocation of nuisance snakes can be a viable approach to reduce humansnake conflict, at least for some species and/or locations. Despite accumulating studies on the effects of translocation on snakes, the factors that influence successful implementation remain unclear and warrant continued investigation. We therefore urge caution in generalizing. Studies vary substantially in their translocation protocols, duration, and assessments of behavior, physiological impacts, and mortality, and all are constrained by relatively small samples.

Supplementary Materials: The following are available online at: https:/ / www.mdpi.com/article / 10.3390/d14020130/s1. Table S1: Rattlesnake telemetry data. Table S2: Codebook for rattlesnake telemetry data.

Author Contributions: A.G.C. and W.K.H. contributed to the conceptualization, study design, and writing, though A.G.C. conducted almost all of the data collection, data curation, and statistical analyses. All authors have read and agreed to the published version of the manuscript.

Funding: This research received no external funding.

Institutional Review Board Statement: This research was approved by the Loma Linda University Institutional Animal Care and Use Committee (protocols 88059 and 8110041) and conducted under permits issued by the California Department of Fish and Wildlife.

Data Availability Statement: The data presented in this study are available in the attached Supplementary Files.

Acknowledgments: We thank Sean Bush and Carl Person for help with snake surgery and Carl Person for assistance tracking the snakes. This research was supported by the Department of Earth and Biological Sciences.

Conflicts of Interest: The authors declare no conflict of interest.

\section{References}

1. Conover, M.R. Resolving Human-Wildlife Conflicts: The Science of Wildlife Damage Management; CRC Press: Boca Raton, FL, USA, 2002.

2. Woodroffe, R.; Thirgood, S.; Rabinowitz, A. The impact of human-wildlife conflict on natural systems. In People and Wildlife, Conflict or Coexistence? Woodroffe, R., Thirgood, S., Rabinowitz, A., Eds.; Cambridge University Press: Cambridge, UK, 2005; pp. 1-12.

3. Frank, B.; Glikman, J.A.; Marchini, S. (Eds.) Human-Wildlife Interactions: Turning Conflict into Coexistence; Cambridge University Press: Cambridge, UK, 2019; Volume 23.

4. Bhatia, S.; Redpath, S.M.; Suryawanshi, K.; Mishra, C. Beyond conflict: Exploring the spectrum of human-wildlife interactions and their underlying mechanisms. Oryx 2020, 54, 621-628. [CrossRef]

5. Malhotra, A.; Wüster, W.; Owens, J.B.; Hodges, C.W.; Jesudasan, A.; Ch, G.; Kartik, A.; Christopher, P.; Louies, J.; Naik, H.; et al. Promoting co-existence between humans and venomous snakes through increasing the herpetological knowledge base. Toxicon $\mathrm{X}$ 2021, 12, 100081. [CrossRef] [PubMed]

6. Benn, B.; Herrero, S. Grizzly Bear mortality and human access in Banff and Yoho National Parks, 1971-1998. Ursus 2002, 13, 213-221.

7. Fernández-Juricic, E.; Vaca, R.; Schroeder, N. Spatial and temporal responses of forest birds to human approaches in a protected area and implications for two management strategies. Biol. Cons. 2004, 117, 407-416. [CrossRef]

8. Carter, E.T.; Attum, O.; Eads, B.C.; Hoffman, A.S.; Kingsbury, B.A. Reducing the potential for human-snake encounters in a recreational park. Hum.-Wildl. Interact. 2014, 8, 158-167.

9. Craven, S.; Barnes, T.; Kania, G. Toward a professional position on the translocation of problem wildlife. Wildl. Soc. Bull. 1998, 26, 171-177.

10. Griffith, B.; Scott, J.M.; Carpenter, J.W.; Reed, C. Translocation as a species conservation tool: Status and strategy. Science 1989, 245, 477-480. [CrossRef]

11. Reinert, H.K. Translocation as a conservation strategy for amphibians and reptiles: Some comments, concerns, and observation. Herpetologica 1991, 47, 357-363.

12. IUCN/SSC. Guidelines for Reintroductions and Other Conservation Translocations; IUCN: Gland, Switzerland, 2013.

13. Sullivan, B.K.; Nowak, E.M.; Kwiatkowski, M.A. Problems with mitigation translocation of herpetofauna. Cons. Biol. 2015, 29, 12-18. [CrossRef] 
14. Bradley, H.S.; Tomlinson, S.; Craig, M.D.; Cross, A.T.; Bateman, P.W. Mitigation translocation as a management tool. Cons. Biol. 2022. [CrossRef]

15. Fitzgerald, L.A.; Walkup, D.; Chyn, K.; Buchholtz, E.; Angeli, N.; Parker, M. The future for reptiles: Advances and challenges in the Anthropocene. Encycl. Anthr. 2018, 3, 163-174.

16. Massei, G.; Quy, R.J.; Gurney, J.; Cowan, D.P. Can translocations be used to mitigate human-wildlife conflicts? Wildlife Res. 2010, 37, 428-439. [CrossRef]

17. Devan-Song, A.; Martelli, P.; Dudgeon, D.; Crow, P.; Ades, G.; Karraker, N.E. Is long-distance translocation an effective mitigation tool for white-lipped pit vipers (Trimeresurus albolabris) in South China? Biol. Cons. 2016, 204, 212-220. [CrossRef]

18. Wolfe, A.K.; Fleming, P.A.; Bateman, P.W. Impacts of translocation on a large urban-adapted venomous snake. Wildl. Res. 2018, 45, 316-324. [CrossRef]

19. Cornelis, J.; Parkin, T.; Bateman, P.W. Killing them softly: A review on snake translocation and an Australian case study. Herpetol. J. 2021, 31, 118-131. [CrossRef]

20. Lee, J.H.; Park, D. Spatial ecology of translocated and resident Amur ratsnakes (Elaphe schrenckii) in two mountain valleys of South Korea. Asian Herpetol. Res. 2011, 2, 223-229.

21. Nash, D.J.; Griffiths, R.A. Ranging behaviour of adders (Vipera berus) translocated from a development site. Herpetol. J. 2018, 28, 155-159.

22. Plummer, M.V.; Mills, N.E. Spatial ecology and survivorship of resident and translocated hognose snakes (Heterodon platirhinos). J. Herpetol. 2000, 34, 565-575. [CrossRef]

23. Read, J.L.; Johnston, G.R.; Morley, T.P. Predation by snakes thwarts trial reintroduction of the endangered woma python Aspidites ramsayi. Oryx 2011, 45, 505-512. [CrossRef]

24. Roe, J.H.; Frank, M.R.; Gibson, S.E.; Attum, O.; Kingsbury, B.A. No place like home: An experimental comparison of reintroduction strategies using snakes. J. Appl. Ecol. 2010, 47, 1253-1261. [CrossRef]

25. Sullivan, B.K.; Kwiatkowski, M.A.; Schuett, G.W. Translocation of urban Gila monsters: A problematic conservation tool. Biol. Cons. 2004, 117, 235-242. [CrossRef]

26. Newman, B.C.; Henke, S.E.; Wester, D.B.; Shedd, T.M.; Perotto-Baldivieso, H.L.; Rudolph, D.C. Determining the suitability of the Jamaican Boa (Chilabothrus subflavus) for short-distance translocation in Cockpit Country, Jamaica. Caribb. J. Sci. 2019, 49, 222-238. [CrossRef]

27. Roe, J.H.; Frank, M.R.; Kingsbury, B.A. Experimental evaluation of captive-rearing practices to improve success of snake reintroductions. Herpetol. Cons. Biol. 2015, 10, 711-722.

28. Heiken, K.H.; Brusch IV, G.A.; Gartland, S.; Escallón, C.; Moore, I.T.; Taylor, E.N. Effects of long distance translocation on corticosterone and testosterone levels in male rattlesnakes. Gen. Comp. Endocrinol. 2016, 237, 27-33. [CrossRef]

29. Cunningham, A.A. Translocations of wildlife disease risks. Cons. Biol. 1996, 10, 349-353. [CrossRef]

30. Linnell, J.D.C.; Aanes, R.; Swenson, J.E.; Odden, J.; Smith, M.E. Translocation of carnivores as a method for managing problem animals: A review. Biodivers. Cons. 1997, 6, 1245-1257. [CrossRef]

31. Hardy, D.L.; Greene, H.W.; Tomberlin, B.; Webster, M. Relocation of nuisance rattlesnakes: Problems using short-distance translocation in a small rural community. Newslet. Col. Herpetol. Soc. 2001, 28, 62-63.

32. Butler, H.; Malone, B.; Clemann, N. The effects of translocation on the spatial ecology of tiger snakes (Notechis scutatus) in a suburban landscape. Wildlife Res. 2005, 32, 165-171. [CrossRef]

33. Hodges, C.W.; Barnes, C.H.; Patungtaro, P.; Strine, C.T. Deadly dormmate: A case study on Bungarus candidus living among a student dormitory with implications for human safety. Ecol. Solut. Evid. 2021, 2, e12047. [CrossRef]

34. Burke, R.L. Relocations, repatriations, and translocations of amphibians and reptiles: Taking a broader view. Herpetologica 1991, $47,350-357$.

35. Chipman, R.; Slate, D.; Rupprecht, C.; Mendoza, M. Downside risk of wildlife translocation. Devel. Biol. 2008, 131, $223-232$.

36. Suarez, M.B.; Ewen, J.G.; Groombridge, J.J.; Beckmann, K.; Shotton, J.; Masters, N.; Hopkins, T.; Sainsbury, A.W. Using qualitative disease risk analysis for herpetofauna conservation translocations transgressing ecological and geographical barriers. Ecohealth 2017, 14, 47-60. [CrossRef]

37. Nowak, E.M.; van Riper, C., III. Effects and Effectiveness of Rattlesnake Relocation at Montezuma Castle National Monument; USGS Forest and Rangeland Ecosystem Science Center: Flagstaff, AZ, USA, 1999.

38. Mccrystal, H.K.; Ivanyi, C.S. Translocation of venomous reptiles in the southwest: A solution-Or part of the problem? In The Biology of Rattlesnakes; Hayes, W.K., Beaman, K.R., Cardwell, M.D., Bush, S.P., Eds.; Loma Linda University Press: Loma Linda, CA, USA, 2008; pp. 395-402.

39. Gibbons, J.W.; Dorcas, M.E. Defensive behavior of Cottonmouths (Agkistrodon piscivorus) toward humans. Copeia 2002, 2002, 195-198. [CrossRef]

40. Kasturiratne, A.; Wickremasinghe, A.R.; de Silva, N.; Gunawardena, N.K.; Pathmeswaran, A.; Premaratna, R.; Savioli, L.; Lalloo, D.G.; de Silva, H.J. The global burden of snakebite: A literature analysis and modelling based on regional estimates of envenoming and deaths. PLoS Med. 2008, 5, e218. [CrossRef]

41. Dart, R.C.; McNally, J.T.; Spaite, D.W.; Gustafson, R. The sequelae of pitviper poisoning in the United States. In Biology of the Pitvipers; Campbell, J.A., Brodie, E.D., Eds.; Selva: Tyler, TX, USA, 1992; pp. 395-404. 
42. Corneille, M.G.; Larson, S.; Stewart, R.M.; Dent, D.; Myers, J.G.; Lopez, P.P.; McFarland, M.J.; Cohn, S.M. A large single-center experience with treatment of patients with crotalid envenomations: Outcomes with and evolution of antivenin therapy. Am. J. Surg. 2006, 192, 848-852. [CrossRef]

43. Smith, J.; Bush, S.P. Envenomations by reptiles in the United States. In Handbook of Venoms and Toxins of Reptiles; Mackessy, S.P., Ed.; CRC Press: Boca Raton, FL, USA, 2010; pp. 475-490.

44. Braband, L.A.; Clark, K.D. Perspectives on wildlife nuisance control: Results of a wildlife damage control firm's customer survey. Proc. East. Wildl. Damage Control Conf. 1991, 5, 34-37.

45. Shine, R.; Koenig, J. Snakes in the garden: An analysis of reptiles "rescued" by community-based wildlife carers. Biol. Cons. 2001, 102, 271-283. [CrossRef]

46. Estes, J.; Terborgh, J.; Brashares, J.S.; Power, M.E.; Berger, J.; Bond, W.J.; Carpenter, S.R.; Essington, T.E.; Holt, R.D.; Jackson, J.B.C.; et al. Trophic downgrading of planet Earth. Science 2011, 333, 301-306. [CrossRef]

47. Sealy, J.B. Ecology and behavior of the timber rattlesnake (Crotalus horridus) in the upper Piedmont of North Carolina: Identified threats and conservation recommendations. In Biology of the Vipers; Schuett, G.W., Höggren, M., Douglas, M.E., Greene, H.W., Eds.; Eagle Mountain Publishing LC: Eagle Mountain, UT, USA, 2002; pp. 561-578.

48. Nowak, E.M.; Hare, T.; McNally, J.T. Management of "nuisance" effects of translocation on Western Diamond-backed Rattlesnakes (Crotalus atrox). In Biology of the Vipers; Schuett, G.W., Höggren, M., Douglas, M.E., Greene, H.W., Eds.; Eagle Mountain Publishing LC: Eagle Mountain, UT, USA, 2002; pp. 533-560.

49. Brown, T.K.; Lemm, J.M.; Montagne, J.-P.; Tracey, J.A.; Alberts, A.C. Spatial ecology, habitat use, and survivorship of resident and translocated Red Diamond Rattlesnakes (Crotalus ruber). In The Biology of Rattlesnakes; Hayes, W.K., Beaman, K.R., Cardwell, M.D., Bush, S.P., Eds.; Loma Linda University Press: Loma Linda, CA, USA, 2008; pp. 377-394.

50. Brown, J.R.; Bishop, C.A.; Brooks, R.J. Effectiveness of short-distance translocation and its effects on Western Rattlesnakes. J. Wildl. Manag. 2009, 73, 419-425. [CrossRef]

51. Johnson, B. Eastern Massasauga Rattlesnake conservation program at Metro Toronto Zoo. In Proceedings of the International Symposium and Workshop on the Conservation of the Eastern Massasauga Rattlesnake; Johnson, B., Menzie, V., Eds.; Metropolitan Toronto Zoo: West Hill, ON, Canada, 1993; pp. 89-93.

52. Hare, T.; McNally, J.T. Evaluation of a rattlesnake relocation program in the Tucson, Arizona, area. Sonoran Herpetol. 1997, 10, 26-31.

53. McNally, J.T. Evaluation of a Rattlesnake Relocation Program (U93009); Report; Arizona Game and Fish Heritage Fund: Phoenix, AZ, USA, 1995. Available online: http://azmemory.azlibrary.gov/cdm/ref/collection/statepubs/id/16661 (accessed on 31 December 2021).

54. King, R.S.; Berg, C.; Hay, B. A Repatriation study of the Eastern Massasauga (Sistrurus catenatus catenatus) in Wisconsin. Herpetologica 2004, 60, 429-437. [CrossRef]

55. Walker, M.L.; Dorr, J.A.; Benjamin, R.J.; Pisani, G.R. Successful relocation of a threatened suburban population of Timber Rattlesnakes (Crotalus horridus): Combining snake ecology, politics, and education. IRCF Reptiles Amphib. 2009, 16, $210-221$.

56. Harvey, D.S.; Lentini, A.M.; Cedar, K.; Weatherhead, P.J. Moving massasaugas: Insight into rattlesnake relocation using Sistrurus c. catenatus. Herpetol. Cons. Biol. 2014, 9, 67-75.

57. Jungen, M.T. Eastern Diamondback Rattlesnake (Crotalus adamanteus) Telemetry Techniques and Translocation. Master's Thesis, Marshall University, Huntington, WV, USA, 2018.

58. Kelley, A.G. The Effectiveness of Long-Distance Translocation of Eastern Diamondback Rattlesnakes (Crotalus adamanteus). Master's Thesis, Marshall University, Huntington, WV, USA, 2020.

59. Reinert, H.K.; Rupert, R.R. Impacts of translocation on behavior and survival of Timber Rattlesnakes, Crotalus horridus. J. Herpetol. 1999, 33, 45-61. [CrossRef]

60. Holding, M.L. Short-Distance Translocation of the Northern Pacific Rattlesnake (Crotalus o. oreganus): Effects on Volume and Neurogenesis in the Cortical Forebrain, Steroid Hormone Concentrations, and Behaviors. Master's Thesis, California Polytechnic State University, San Louis Obispo, CA, USA, 2011.

61. Holding, M.L.; Frazier, J.A.; Taylor, E.N.; Strand, C.R. Experimentally altered navigational demands induce changes in the cortical forebrain of free-ranging Northern Pacific Rattlesnakes (Crotalus o. oreganus). Brain Behav. Evol. 2012, 79, 144-154. [CrossRef]

62. Holding, M.L.; Frazier, J.A.; Taylor, E.N.; Strand, C.R. Physiological and behavioral effects of repeated handling and short-distance translocations on free-ranging Northern Pacific Rattlesnakes (Crotalus oreganus oreganus). J. Herpetol. 2014, 48, 233-239. [CrossRef]

63. Jennings, M.R.; Hayes, M.P. Amphibian and Reptile Species of Special Concern in California; California Department of Fish and Game, Inland Fisheries Division: Rancho Cordova, CA, USA, 1994.

64. Dugan, E.A.; Figueroa, A.; Hayes, W.K. Home range size, movements, and mating phenology of sympatric Red Diamond (Crotalus ruber) and Southern Pacific (C. oreganus helleri) rattlesnakes in southern California. In The Biology of Rattlesnakes; Hayes, W.K., Beaman, K.R., Cardwell, M.D., Bush, S.P., Eds.; Loma Linda University Press: Loma Linda, CA, USA, 2008 ; pp. $353-364$.

65. Halama, K.J.; Malisch, A.J.; Aspell, M.; Rotenberry, J.T.; Allen, M.F. Modeling the landscape niche characteristics of Red Diamond Rattlesnakes (Crotalus ruber): Implications for biology and conservation. In The Biology of Rattlesnakes; Hayes, W.K., Beaman, K.R., Cardwell, M.D., Bush, S.P., Eds.; Loma Linda University Press: Loma Linda, CA, USA, 2008; pp. 463-472.

66. Cowling, R.M.; Rundel, P.W.; Lamont, B.B.; Arroyo, M.K.; Arianoutsou, M. Plant diversity in Mediterranean-climate regions. Trends Ecol. Evol. 1996, 11, 362-366. [CrossRef] 
67. Western Regional Climate Center (undated). Redlands, California (047306): Period of Record Monthly Climate Summary: 04/01/1898 to 05/17/2016. Available online: https:/ / wrcc.dri.edu/cgi-bin/cliMAIN.pl?ca7306 (accessed on 31 December 2021).

68. Quinn, H.; Jones, J. Squeeze box technique for measuring snakes. Herpetol. Rev. 1974, 5, 35.

69. Rasband, W.S. ImageJ; National Institutes of Health: Bethesda, MD, USA, 1997.

70. Hardy, D.L.; Greene, H.W. Surgery on rattlesnakes in the field for implantation of transmitters. Sonoran Herpetol. $1999,12,25-27$.

71. Reinert, H.K.; Cundall, D. An improved surgical implantation method for radio-tracking snakes. Copeia 1982, 1982, 702-705. [CrossRef]

72. R Core Team. R: A Language and Environment for Statistical Computing; R Foundation for Statistical Computing: Vienna, Austria, 2021.

73. Calenge, C. The package "adehabitat" for the R software: A tool for the analysis of space and habitat use by animals. Ecol. Model. 2006, 197, 516-519. [CrossRef]

74. Getz, W.M.; Wilmers, C.C. A local nearest-neighbor convex-hull construction of home ranges and utilization distributions. Ecography 2004, 27, 489-505. [CrossRef]

75. Getz, W.M.; Fortmann-Roe, S.; Cross, P.C.; Lyons, A.J.; Ryan, S.J.; Wilmers, C.C. LoCoH: Nonparameteric kernel methods for constructing home ranges and utilization distributions. PLOS ONE 2007, 2, e207. [CrossRef]

76. Gregory, P.T.; Macartney, J.M.; Larsen, K.W. Spatial patterns and movements. In Snakes: Ecology and Evolutionary Biology; Seigel, R.A., Collins, J.T., Novak, S.S., Eds.; Blackburn Press: Caldwell, NJ, USA, 2001; pp. 366-395.

77. Gallucci, M. GAMLj: General Analysis for Linear Models. 2019. Available online: https://gamlj.github.io/ (accessed on 31 December 2021).

78. Nakagawa, S.; Schielzeth, H. A general and simple method for obtaining $\mathrm{R}^{2}$ from generalized linear mixed-effects models. Meth. Ecol. Evol. 2013, 4, 133-142. [CrossRef]

79. Zuur, A.F.; Ieno, E.N.; Elphick, C.S. A protocol for data exploration to avoid common statistical problems. Methods Ecol. Evol. 2010, 1, 3-14. [CrossRef]

80. Bates, D.; Macchler, M.; Bolker, B.; Walker, S.; Christensen, R.H.B.; Singmann, H.; Dai, B.; Scheipl, F.; Grothendieck, G.; Green, P.; et al. Test Fitted Model for (near) Singularity. R Documentation. 2015. Available online: https://search.r-project.org/CRAN/ refmans/lme4/html/isSingular.html (accessed on 31 December 2021).

81. Therneau, T. A Package for Survival Analysis in R. 2021. Available online: https:// cran.r-project.org/package=survival (accessed on 31 December 2021).

82. Kaplan, E.L.; Meier, P. Nonparametric estimation from incomplete observations. J. Am. Stat. Assoc. 1958, 53, 457. [CrossRef]

83. Pollock, K.H.; Winterstein, S.R.; Bunck, C.M.; Curtis, P.D. Survival analysis in telemetry studies: The staggered entry design. J. Wildl. Manag. 1989, 53, 7. [CrossRef]

84. Robertson, H.A.; Westbrooke, I.M. A Practical Guide to the Management and Analysis of Survivorship Data from Radio-Tracking Studies; Science \& Technical Publishing, Department of Conservation: Wellington, New Zealand, 2005.

85. Cox, D.R. Regression models and life-tables. J. R. Stat. Soc. Ser. B (Methodol.) 1972, 34, 187-220. [CrossRef]

86. Miller, H.W.; Johnson, D.H. Interpreting the results of nesting studies. J. Wildl. Manag. 1978, 42, 471-576. [CrossRef]

87. Mathew, A.; Pandey, M.; Murthy, N.S. Survival analysis: Caveats and pitfalls. Eur. J. Surg. Oncol. 1999, 25, 321-329. [CrossRef]

88. Grambsch, P.M.; Therneau, T.M. Proportional hazards tests and diagnostics based on weighted residuals. Biometrika 1994, 81, 515-526. [CrossRef]

89. Duvall, D.; Schuett, G. Straight-line movement and competitive mate searching in prairie rattlesnakes, Crotalus viridis viridis. Anim. Behav. 1997, 54, 329-334. [CrossRef]

90. Glaudas, X.; Rodríguez-Robles, J.A. Vagabond males and sedentary females: Spatial ecology and mating system of the Speckled Rattlesnake (Crotalus mitchellii). Biol. J. Linn. Soc. 2011, 103, 681-695. [CrossRef]

91. Jellen, B.C.; Shepard, D.B.; Dreslik, M.J.; Phillips, C.A. Male movement and body size affect mate acquisition in the Eastern Massasauga (Sistrurus catenatus). J. Herpetol. 2007, 41, 451-457. [CrossRef]

92. Petersen, C.E.; Goetz, S.M.; Dreslik, M.J.; Kleopfer, J.D.; Savitzky, A.H. Sex, mass, and monitoring effort: Keys to understanding spatial ecology of Timber Rattlesnakes (Crotalus horridus). Herpetologica 2019, 75, 162-174. [CrossRef]

93. Aldridge, R.D.; Duvall, D. Evolution of the mating season in the pitvipers of North America. Herpetol. Monogr. 2022, 16, 1-25. [CrossRef]

94. Dreslik, M.J.; Shepard, D.B.; Jellen, B.C.; Phillips, C.A. Movement and home range of the Eastern Massasauga (Sistrurus catenatus) at its southern range limit. In The Biology of Rattlesnakes II; Dreslik, M.J., Hayes, W.K., Beaupre, S.J., Mackessy, S.P., Eds.; ECO Herpetological Publishing and Distribution: Rodeo, NM, USA, 2017; pp. 168-178.

95. Figueroa, A.; Dugan, E.A.; Hayes, W.K. Behavioral ecology of neonate Southern Pacific Rattlesnakes (Crotalus oreganus helleri) tracked with externally-attached transmitters. In The Biology of Rattlesnakes; Hayes, W.K., Beaman, K.R., Cardwell, M.D., Bush, S.P., Eds.; Loma Linda University Press: Loma Linda, CA, USA, 2008; pp. 365-376.

96. Stamps, J.A.; Swaisgood, R.R. Someplace like home: Experience, habitat selection and conservation biology. Appl. Anim. Behav. Sci. 2007, 102, 392-409. [CrossRef]

97. Nowak, E.M.; Greene, H.W. Rattlesnake conservation in the 21st century. In Rattlesnakes of Arizona, Conservation, Behavior, Venom, and Evolution; Schuett, G.W., Feldner, M.J., Smith, C.F., Reiserer, R.S., Eds.; ECO Herpetological Publishing and Distribution: Rodeo, NM, USA, 2017; Volume 2, pp. 413-454. 
98. Bateman, H.L.; Brown, J.A.; Larson, K.L.; Andrade, R.; Hughes, B. Unwanted residential wildlife: Evaluating social-ecological patterns for snake removals. Glob. Ecol. Cons. 2021, 27, e01601. [CrossRef]

99. Bonnet, X.; Lecq, S.; Lassay, J.L.; Ballouard, J.M.; Barbraud, C.; Souchet, J.; Mullin, S.J.; Provost, G. Forest management bolsters native snake populations in urban parks. Biol. Cons. 2016, 193, 1-8. [CrossRef]

100. Hayes, W.K. Book review: Rattlesnakes of Arizona, Volume 2: Conservation, Behavior, Venom, and Evolution. Herpetol. Rev. 2017, $48,870-873$.

101. Bonnet, X.; Naulleau, G.; Shine, R. The dangers of leaving home: Dispersal and mortality in snakes. Biol. Cons. 1999, 89, 39-50. [CrossRef]

102. Shepard, D.B.; Dreslik, M.K.; Jellen, B.C.; Phillips, C.A. Reptile road mortality around an oasis in the Illinois Corn Desert with emphasis on the endangered Eastern Massasauga. Copeia 2008, 2008, 350-359. [CrossRef]

103. Cardwell, M.D.; Bush, S.P.; Clark, R.T.; Dugan, E.A. Males Biting Males: Does Testosterone Shape Both Sides of the Snakebite Equation? Undated Poster. Available online: https://www.researchgate.net/profile/Michael-Cardwell-2/publication/26647072 8_Males_biting_males_does_testosterone_shape_both_sides_of_the_snakebite_equation/links/54dd0ba10cf25b09b912e9cd / Males-biting-males-does-testosterone-shape-both-sides-of-the-snakebite-equation.pdf (accessed on 31 December 2021).

104. Macartney, J.M.; Gregory, P.T.; Larsen, K.W. A tabular survey of data on movements and home ranges of snakes. J. Herpetol. 1988, 22, 61-73. [CrossRef] 